\title{
ÉTICA, DERECHO Y FECUNDACIÓN ASISTIDA
}

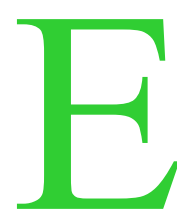

n 1978 se anunció a través de los medios publicitarios el nacimiento de Louise Brown, primer bebé logrado en Inglaterra por fecundación in vitro (FIV) y traslado de embrión (TE). Desde entonces han sido numerosos los nacimientos por este método y las clínicas especializadas se han multiplicado por el mundo. En 1984, dos casos llamaron la atención de la opinión pública. El primero fue el nacimiento de la niña australiana Zoe Leyland, el 13 de mayo, a partir de un embrión que había permanecido congelado durante dos meses. El segundo, conocido como affair Parpalaix, llevó al Tribunal de Grande Instance de Créteil a resolver favorablemente, por sentencia del $1 .^{\circ}$ de agosto, la demanda de la viuda Corine Parpalaix a que se le entregara el semen depositado de su esposo para su inseminación. Intentada la inseminación post mortem, fracasó.

Pero, probablemente, el caso más comentado haya sido el de Baby $M$. Como se sabe, el 6 de febrero de 1985 se celebró un contrato de maternidad subrogada (suplente o sustituta) entre la señora Whitehead, su esposo y el señor Stern, padre natural o biológico. La señora Whitehead fue inseminada artificialmente con el semen del señor Stern procreando una niña que nació el 27 de marzo de 1986. Establecida la controversia legal, que no es el caso detallar ahora, el Tribunal inferior resuelve el 31 de mayo de 1987 que el contrato es válido, beneficiando así al padre biológico. Sin embargo, ante la apelación presentada por la señora Whitehead, el Tribunal Supremo del Estado de New Jersey resolvió el 3 de febrero de 1988 revocando unánimemente, casi en su totalidad, la decisión del Tribunal inferior. En consecuencia, se declaró que la madre subrogada -biológica y gestante- era la madre legal de la criatura. A su vez, la adopción de ésta por la señora Stern se declaró inválida e ineficaz. 
Así los hechos, no debe extrañar que a partir de los primeros éxitos obtenidos por inseminación artificial (IA), los avances alcanzados y las perspectivas de futuro sean asombrosos $^{1}$. Como era de esperarse, paralelamente a los avances técnicos, se ha desarrollado una fecunda reflexión moral que ha puesto a prueba los principios de cada una de las grandes teorías éticas, oscilando las respuestas entre las que pugnan por un rechazo a toda interferencia de la técnica en los procesos naturales reducidos, por lo general, a los biológicos, hasta las que aceptan, indiscriminadamente, cualquier interferencia bajo criterios crudamente utilitarios.

La variedad de respuestas no debe llamarnos la atención si pensamos un poco en la complejidad de los problemas. En el supuesto de la inseminación artificial conyugal (IAC), ¿se justifica éticamente el procedimiento?, ¿se justifica la inseminación homóloga con semen del marido luego de su fallecimiento, la llamada inseminación post mortem? En el caso de la inseminación artificial con donante (IAD), de nueva cuenta ¿se justifica éticamente el procedimiento?, ¿debe quedar abierta la posibilidad de inseminación para las mujeres no casadas actualmente (solteras, viudas, divorciadas, concubinas, lesbianas) como una muestra de respeto al derecho de toda mujer a procrear?, ¿debe mantenerse el anonimato del donante o tiene derecho el hijo a conocer su filiación genética? Por lo que respecta a la fecundación in vitro, $\mathrm{y}$ desde el punto de vista del embrión logrado, ¿cuál debe ser su estatuto ético-antropológico?, ¿es una cosa?, ¿es una persona?, ¿puede ser objeto de donación, compra-venta o adopción?, ¿se justifica su congelamiento?, ¿puede ser manipulado para efectos de investigación o experimentación? Pero, además, si le fuera imposible a la madre gestar al embrión, ¿se justifica éticamente su implantación en el útero de otra mujer, la llamada con propiedad, maternidad sustituta?, ¿qué criterio se debe

${ }^{1}$ Por mencionar sólo algunos de estos avances: la separación de los espermatozoides más activos en un intento de asegurar que sólo los más saludables lleguen a fecundar el óvulo; el rompimiento de la capa externa del óvulo por medios químicos reduciendo así el número de espermatozoides de calidad que se precisan para conseguir la fecundación; la transferencia intratubárica de gametos (TIG); la congelación y descongelación de óvulos y embriones por largos períodos de tiempo; la microcirugía que trae como resultado idénticos gemelos o trillizos; la clonización de embriones que posibilitaría una descendencia numerosa e idéntica; la inyección de material genético una vez identificadas las secuencias de DNA asociadas con varias enfermedades genéticas; la utilización médica del tejido fetal y la transferencia de células de un embrión de 2 ó 3 semanas a niños a adultos que padecen alguna anormalidad que afecta las funciones vitales del cuerpo: el trasplante de ovarios como otro recurso para superar la esterilidad; la placenta artificial para mantener con vida fetos expulsados por aborto espontáneo cuando tiene diez semanas, etc. 
seguir para determinar la maternidad? ¿el genético?, ¿el gestante?, ¿el intencional-afectivo?

A los cuestionamientos éticos se suman los problemas jurídicos con todas sus sutilezas, por lo demás necesarias si se quieren proteger adecuadamente los derechos de todos los actores implicados: las personas que solicitan el método, los hijos nacidos por el método, y los terceros que pueden o no intervenir, donantes o madres sustitutas. La nueva realidad, qué duda cabe, es un reto a la imaginación del jurista quien se ha visto en la necesidad de replantear algunas instituciones clásicas del derecho civil ${ }^{2}$. Así por ejemplo, con base en la legislación vigente y ante la posibilidad de la fecundación post mortem se plantea la situación de que el hijo pudiera ser genéticamente conyugal pero jurídicamente extramatrimonial si su nacimiento tuviera lugar después de los 300 días posteriores a la muerte del esposo, plazo que señala la ley (324-II C.C.) para presumir que se trata de hijo de los cónyuges. La interrogante que surge es que en el caso de que la viuda probara que fue fecundada con semen de su esposo ¿podría considerarse a ese hijo como fuera del matrimonio? Además, los hijos que no estén concebidos al tiempo de la muerte del autor de la herencia son incapaces de adquirir por testamento a causa de su falta de personalidad jurídica (1314 C.C.) con lo cual el hijo póstumo quedaría excluido, ¿es justa esta situación para el hijo?

La revisión jurídica se hace necesaria también con respecto a los problemas que suscita la IAD y FIV con donante. Pensemos en lo relativo al reconocimiento de la criatura. Los artículos 325 y 326 C.C. no pueden ni deben aplicarse a esta situación. Por otro lado, ¿qué figura jurídica sería la apropiada para determinar la relación padre-hijo?, ¿la adopción? Hasta la fecha la figura de la adopción

${ }^{2}$ Para los problemas ético-jurídicos que plantea la genética actual se puede consultar con provecho: Eduardo Zannoni, Inseminación artificial y fecundación extrauterina, Astrea, Bs.As. 1978; Alberto Di Ció, La inseminación artificial y el derecho de la familia, Belgrano, Bs.As., 1984; Manuel Chávez Asencio, La Familia en el Derecho, Porrúa, México, 1978, T. III -de los pocos juristas mexicanos que han tratado el tema con lucidez de acuerdo con nuestra legislación vigente y a quien personalmente debemos muchos de los cuestionamientos jurídicos-: Pedro Silva Ruiz. «El derecho de familia y la inseminación artificial in vivo e in vitro», Revista del Colegio de Abogados de Puerto Rico, Vol. 48, enero-mayo, 1987, n. ${ }^{\circ}$ 1, págs. 25-35: «El contrato de maternidad sustituida o suplente o subrogada, la maternidad de alquiler», Boletín de Información del Ministerio de Justicia, Madrid, España, febrero, 1987, n. $^{\circ} 447$. De especial importancia para el tema son las ponencias presentadas tanto en el II Congreso Mundial Vasco (28-IX al 2-X de 1987) con el título La filiación a finales del siglo XX, como en el Congreso Hispanoamericano de Derecho de Familia celebrado en Cáceres, España (octubre-noviembre de 1987) con el título La genética actual y el derecho de familia. 
supone al menor ya nacido (implícito en 390 C.C.) pero aquí estamos hablando de un preembrión o germen. Por tanto, o se inventa una nueva figura jurídica o se extiende la posibilidad de adopción hasta el preembrión. Asimismo, por lo que hace a la posibilidad de contradecir la maternidad, la mujer queda totalmente imposibilitada (60 C.C.), pero ¿qué sucedería en el supuestos de que se engañe a la mujer haciéndole creer que el óvulo usado para la fecundación fue el suyo y resulta que fue de una mujer extraña?

La situación de la madre sustituta en el sentido propio de este término, cuando únicamente gesta a la criatura pero no aporta su óvulo, plantea otros problemas interesantes. Por lo pronto, obliga a replantear el principio de que la filiación con relación a la madre resulta del solo hecho del nacimiento (360 C.C.), ya que hay un desfase entre el origen biológico del niño (criterio para determinar la filiación consanguínea) y su gestación.

Por último, para cerrar estos planteamientos jurídicos, en la legislación se plantea el deseo de que el hijo nazca en el seno de una familia y más concretamente dentro del matrimonio. Sin embargo, ¿podría hacerse extensiva la posibilidad de que una pareja heterosexual estable no casada accediera a la IA y FIV? No olvidemos que la legislación mexicana dio un gran paso en 1983 al eliminar la distinción entre hijos legítimos e hijos ilegítimos y sustituirla por la de hijos dentro del matrimonio e hijos fuera del matrimonio, reconociendo para estos últimos el derecho a llevar el apellido paterno de sus progenitores, a ser alimentados y a percibir la porción hereditaria (389 C.C.). Explícitamente el 383 C.C. reproduce las presunciones del 324 C.C. ahora para los hijos de concubinario y concubina. Y, si bien es cierto que el acento de estos artículos está puesto en la protección de los hijos, indirectamente, existe un reconocimiento al hecho muy extendido en México del concubinato. El acceso de concubinos a la IA y FIV podría ser una prolongación de ese reconocimiento que, sin duda, beneficiaría a muchas parejas.

Pues bien, los problemas a nivel jurídico podrían multiplicarse, pero no obstante lo importante que resulta este punto de vista, nos limitaremos a señalar en lo que resta de este escrito algunas justificaciones éticas de los problemas planteados inicialmente. Pienso que la ética que mejor responde a tales problemas es una ética liberal que, a grandes rasgos, toma como punto de partida a la persona moral, su dignidad y autonomía, así como la posibilidad de satisfacer distintos planes de vida.

La humanidad de la persona moral se nos manifiesta como una realidad simultáneamente biológica y racional, individual y comunitaria, fin en sí misma y autorrealizable. Esto significa, entre otras cosas, que la persona no se agota en su estructura y dinamismo físicos; 
por lo tanto, el orden biológico no es un criterio suficiente de moralidad. Sacralizar el carácter biológico de la persona ha llevado a no pocos moralistas a excluir todo tipo de intervención humana en los procesos naturales dando lugar a una ética dogmática, absolutista y, por tanto, inhumana. Si la técnica auxilia a la persona en la satisfacción de sus planes de vida y permite a través de los métodos de fecundación asistida superar una carencia grave como es la esterilidad, que afecta entre un 10 y 15 por 100 de las parejas en edad de procrear, no hay razón para prohibir su puesta en práctica. La IA, FIV y TIG, no son censurables, más bien suplen deficiencias en el proceso reproductor de la pareja.

Pero, de igual manera, si privilegiamos la racionalidad de la persona sin limitación alguna a sus deseos, intereses o preferencias podría conducirnos a una falta de respecto a su dignidad. Por lo que, si los métodos de fecundación asistida tienen como propósito fundamental superar la esterilidad para facilitar la procreación, su aplicación tiene sentido cuando otros medios terapéuticos se han descartado por inadecuados o ineficaces. De no mediar la esterilidad no se justifica su uso para satisfacer los deseos de la pareja por razones de moda, esnobismo o fines estéticos.

La pareja estable es el ámbito ético-jurídico-social aceptable para la realización de los métodos de fecundación asistida. Entiendo por pareja estable a la pareja heterosexual que adquiere un compromiso público y razonablemente permanente de vida en común y que se propone como fin la mutua promoción. Deliberadamente me ubico en el derecho del hijo a una vida estable y rechazo la idea de que exista en la mujer un derecho al hijo que haría de este último, que es fin en sí mismo, un medio al servicio de los deseos o intereses de otra persona. Desde este punto de vista, las parejas homosexuales, la mujer soltera y las personas en unión inestable no deben tener acceso a preembriones, semen u óvulos donados ${ }^{3}$. Reitero, el derecho de toda mujer a ser madre es un derecho prima facie. La maternidad debe entenderse en función del hijo y no al revés.

Es cierto que la carencia actual de regulación de las condiciones en que se desarrollan las uniones de facto por lo que hace a un acuerdo sobre el tiempo aceptable de duración, la ausencia de una aceptación pública y los derechos y obligaciones que contrae la pareja, no ofrece un contexto de seguridad adecuado para el buen

${ }^{3}$ En este punto recogemos las ideas expresadas por buena parte de la doctrina, así como por la mayoría de las Comisiones, en especial, los informes del Consejo de Europa y el informe Warnock en el Reino Unido, ambos de 1984. También, las propuestas de ley italiana y francesa, y la ley sueca que entró en vigor el 1. ${ }^{\circ}$ de marzo de 1985. 
desarrollo del hijo. Pero si éstas son las razones para impedir su acceso a los métodos de fecundación asistida, pienso que no son insuperables y más que un rechazo debe hacerse un esfuerzo ético y jurídico para hacer compatible el derecho de la pareja estable a formar familia y el derecho del hijo a un clima de seguridad y aceptación social.

Con respecto al estatuto antropológico del preembrión su índole humana se encuentra asegurada por hechos biológicos, como son el correspondiente código y mensaje genéticos que lo hacen un ser individual e independiente del organismo materno pese a que su autonomía y personalización la adquirirá gradualmente en un período posterior. Por tanto, los preembriones, que corresponden a la fase preorganogénesis desde la fecundación hasta aproximadamente 14 días más tarde, cuando anida establemente en el interior del útero, no deben ser objeto de donación, compra-venta o depósito, contratos que suponen un bien patrimonial. Tampoco es justificable éticamente la utilización de preembriones con fines de experimentación (partenogénesis, fusión de preembriones entre sí, intercambio genético con otras especies para producir híbridos, la transferencia en el útero de otra especie animal, etc.), o para fines industriales. Pero no veo impedimento alguno para que, por una parte, se puedan usar los gametos (semen y óvulo) por separado con fines de investigación o experimentación y, por otra, para que el mismo preembrión pueda ser objeto de investigación con fines de diagnóstico (valoración de su viabilidad o no, o detención de enfermedades hereditarias) o terapéuticas (tratar una enfermedad o impedir su transmisión). Por otra parte, y de acuerdo con Zannoni ${ }^{4}$, dada la dignidad del preembrión no se justifica que se le exponga a un estado de incertidumbre y desamparo. Me refiero a los llamados «embriones sobrantes».

Pienso que toda FIV debe realizarse con el fin de implantar el o los embriones en el útero materno y no someterlos a situaciones aleatorias. Por tanto, la admisión de fertilizaciones múltiples es aceptable a condición de que todos los preembriones sean implantados. Si la pareja no está en condiciones actuales de llevar adelante el embarazo, no se justifica realizar fertilizaciones ahora para posibilitar implantaciones después.

Con respecto a la IA (Inseminación Artificial) y a la FIVTE (Fecundación In Vitro y Traslado de Embrión) homóloga o heteróloga, esto es, con semen del marido (o del hombre en la pareja estable) o con gametos masculinos o femeninos de donantes, no presentan

${ }^{4}$ Eduardo Zannoni, «La genética actual y el derecho de familia», ponencia presentada en el Congreso Hispanoamericano de Derecho de Familia. 
ningún conflicto ético. Se parte del supuesto de que no existe un rechazo de la pareja a la cópula como medio ordinario para la procreación, sino de la existencia de una carencia (la esterilidad) que la imposibilita. Los métodos de fecundación asistida se utilizan, entonces, como una situación remedial y supletoria.

La IA post mortem con semen del marido se justifica éticamente dada la fuerza moral e institucional del matrimonio o de la pareja estable, en su caso. Coincido en esta valoración con los puntos de vista expresados por Rivero Hernández 5 . Contra la IA post mortem se aduce -como cuando se trata de mujer sola- que el hijo se vería condenado a nacer y vivir sin padre, lo que va en contra de su interés y bienestar. En efecto, el hijo tiene derecho a tener padre y madre pero «quizá el derecho del hijo en este terreno no es tanto el de tener padre y madre como dos seres que le acompañen físicamente, sino a que ambos le proporcionen una serie de cosas que hagan visible una existencia a la que le han traído por exclusive decisión de aquéllos». Por otro lado, la situación de la IA p.m. no es igual a la de mujer sola: «En este caso el hijo nace (no sólo vivirá) sin padre. En aquél el hijo si va a tener padre; no lo conocerá materialmente, no disfrutará de él, su protección y afecto, pero no es hijo sin padre, o de padre desconocido». El hijo tendría una relación de filiación y, con la familia del padre, otra de parentesco. Además el hijo será hijo de matrimonio, si se demuestra que fue engendrado por el marido, aun pasados los 300 días, pues «el consentimiento para la fecundación p.m. del marido fallecido, conjugado con la decisión de la viuda a ser inseminada, responden a un proyecto común de dar vida a un hijo de ambos» y creo que esta voluntad es el factor determinante para que se pueda justificar la inseminación y hablar de hijo dentro del matrimonio. Además del consentimiento del marido, entre otros requisitos, habría que exigir que la inseminación tuviera lugar dentro de un plazo razonable (lo que hablaría de la buena fe de la pareja): un año, prorrogable si hay causa justificada, como podría ser alguna enfermedad de la mujer.

Por último, por lo que respecta a la maternidad subrogada, cabe hacer algunos comentarios. Sabemos que dado el embrión por FIV se procede a su traslado (TE) en el útero de la madre. Pero, en el caso de que ésta no pudiera gestarlo ¿sería justificable, éticamente, su traslado al útero de otra mujer para que se geste? El supuesto que estoy considerando es el de la gestación por otra mujer pero con aportación por la pareja de gametos. Con respecto, entonces, a la

${ }^{5}$ Véase Francisco Rivero Hernández, «La fecundación artificial post mortem», ponencia presentada en el Congreso Hispanoamericano de Derecho de Familia. 
sola gestación en útero extraño no veo impedimento ético alguno para que se pueda llevar a cabo. Como es obvio, la noción que está implícita en la afirmación anterior es la de la maternidad y aunque los informes y los proyectos de legislación se están inclinando a privilegiar la maternidad de gestación, los criterios no son tan claros. Desde mi punto de vista, la razón formal, lo que especifica la maternidad es la intención, deseo o voluntad de ser madre, con todo lo que esta intención significa en términos de cuidado, afecto y alimentos. Esta razón es determinante, por ejemplo, para justificar la adopción y no sólo la adopción limitada, que es la que acepta nuestra legislación vigente (402 C.C.), sino la adopción plena por la cual el niño se integra totalmente a la familia de los adoptantes. Pienso que la gestación que indudablemente conlleva un valor físico y afectivo reforzador y que contribuye a la plenitud de la maternidad, no es un elemento necesario para su determinación. Bajo ciertas condiciones -y entre ellas una de las más importantes es la no mediación de un convenio lucrativo- no veo razón para que no se pueda auxiliar a la mujer que está incapacitada para gestar, a través de un útero sustituto. Coincido en este punto con Merino Gutiérrez cuando afirma que «en los casos de utilización de útero ajeno la gestación sustituta es secundaria respecto al material genético incorporado. En esta línea sería partidario de inscribir la filiación como matrimonial o no matrimonial en las condiciones ya señaladas por algunos autores de que concurra un acuerdo previo, antes de la implantación del embrión, que conste por escrito en documento público, entre la pareja y la mujer portadora; un documento del centro donde se practicó la implantación asegurando que el material genético corresponde efectivamente a la pareja y, por último, la ausencia de oposición de la gestante sustituta una vez que ya ha dado a luz» ${ }^{6}$. Quizá no esté lejos el día en que se pueda gestar la criatura a través de placenta artificial desde las primeras semanas lo que, sin duda sería otra alternativa para solucionar los casos de incapacidad gestativa.

${ }^{6}$ A. Merino Gutiérrez, «Los consentimientos relevantes y las técnicas de reproducción asistida», ponencia presentada en el II Congreso Mundial Vasco.

\section{DOXA-14 (1993)}

